\title{
Green Road Approach for the Sustainable Development in India
}

By

\author{
AppaRoa G. ${ }^{{ }^{*}}$, Rajiv Kumar ${ }^{2}$, Amar D.D. ${ }^{3}$, Ryntathiang T.L. ${ }^{4}$,
}

\begin{abstract}
:
Road transport is considered to be one of the cost effective and preferred modes of transport for both freight and passengers. India has an extensive road network of 4.24 million $\mathrm{km}-$ the second largest in the world (MoRTH, 2005). The National Highways have a total length of $70,934 \mathrm{~km}$ and serve as the arterial road network of the country. It is estimated that more than 70 per cent of freight and 85 per cent of passenger traffic in the country is being handled by roads. While Highways/ Expressways constitute only about 2 $\%$ of the length of all roads, rest are state highway, major district road, district roads and rural and other road which is consider as low volume road.

Growing public awareness of climate change requires transportation professionals to integrate green concepts into the transportation planning, design, construction, and operation processes.

Green highways are a relatively new concept although the implementation of technologies involved in green highway design has been encouraged for many years. A green road may not look like normal road at first glance, but with closer inspection a driver will notice subtle difference. More plant life grows along the shoulder, and more trees are planted as wildlife buffers and ridding quality. In towns, highways become more aesthetically pleasing, and in rural areas highways become a more natural part of the environment a green highway can be defined by five broad topics such as Conservation and Ecosystem Management, Water Shed Driven Strong Water Management, Life Cycle Energy and Emissions Reduction, Recycles Reuse And Renewable, Overall Societal Benefits.

This paper describes the factor affecting of green road and construction process of wearing course of pavement through Microsurfacing which reduce the both direct and indirect cost. Microsurfacing is environmental friendly which reduce the greenhouse gas and fuel consummation.
\end{abstract}

Key words: Green Road Approach, Indian Road \& Sustainable Development

\section{Introduction}

Road transport is considered to be one of the cost effective and preferred modes of transport for both freight and passengers. India has an extensive road network of 4.24 million $\mathrm{km}$ - the second largest in the world (MoRTH, 2005).

${ }^{1 *}$ Assistant Professor, Dept. of Civil Engg., GITAM University, Hyderabad-500072

2 \&3M-Tech Students, Dept. of Civil Engg, IIT Guwahati, Guwahati - 781039

${ }^{4}$ Associate Professor, Dept. of Civil Engg, IIT Guwahati, Guwahati - 781039,

$*$ Crossponding author: 
The National Highways have a total length of $70,934 \mathrm{~km}$ and serve as the arterial road network of the country. It is estimated that more than 70 per cent of freight and 85 per cent of passenger traffic in the country is being handled by roads. While Highways/ Expressways constitute only about 2per cent of the length of all roads, rest are state highway, major district road, district roads and rural and other road which is consider as low volume road.

Growing public awareness of climate change requires transportation professionals to integrategreen concepts into the transportation planning, design, construction, and operation processes.

Green highways are a relatively new concept although the implementation of technologies involved in green highway design has been encouraged for many years. More plant life grows along the shoulder, and more trees are planted as wildlife buffers and ridding quality. In towns, highways become more aesthetically pleasing, and in rural area highways become a more natural part of the environment a such as Conservation and Ecosystem Management, Water Shed Driven Strong Water Management, Life Cycle Energy and Emission Reduction,

Recycle Reuse and renewable, Overall Societal Benefits.

Conservation of non-renewable resources and energy, together with reduced environmental pollution and working conditions are global issues that are becoming increasingly important to civil engineers. As a result, authorities in various countries are creating legislation and authorities to reduce energy consumption by using cold mix construction and recycling of pavement (Greenroads, 2009). These incentives are bound to shape to development of new processes in the road construction especially in the section where the highest consumption occurs, i.e. in the hot mixes asphalt production. As we know that for hot mix production involves the use of fossil fuel both as a raw material and energy source, hot mix plants vary according to their age and efficiency, on average it takes about 10 cubic meters of the natural gas has about $0.525 \mathrm{~kg}$ of carbon (Grade 9 science), one tonne of HMA will produce about $5.25 \mathrm{~kg}$ of carbon. Using cold mix and cold mix recycling we can stop this carbon emission. According to Dorchies (2008), for the production of aggregate includes the quarrying, hauling, crushing and screening, the GHG emission range is 2.5 to10 $\mathrm{kgCO}_{2} / \mathrm{t}$ and for asphalt it is $221 \mathrm{~kg} \mathrm{CO} / \mathrm{t}$.

In this paper, the focus is on cold mix technology (micro-surfacing) produced in field at temperature greater than $10^{\circ} \mathrm{C}$, environmental impact, and advantages of cold mix recycling.

Micro surfacing has been used in Germany, Spain, and France since 1976 and was introduced to the United States in 1980. Micro-surfacing has been introduced in India since 1999-2000, though the technology has been in use the world over 
for a very long time as a routine form of maintenance in preference to conventional overlays of hot mix. This has been introduced in India under the brand name of Macro-seal, by Yala construction and Elsamex SA, Spain (Vice president, Yala construction, 29 November 2010). A study was initiated for use of bitumen emulsion to maintain Delhi roads by the state government as a suitable alternative method for maintenance of roads in light of ban on hot mix plants imposed by the Supreme Court. The study was conducted approximately ten year back, by Elsamex S.A, Spain with the active involvement of Central Road Research Institute (CRRI) Delhi. In the study report, the specifications for the use of cold emulsion for maintaining various types of roads were standardized with latest state of the art technology. The study report was utilized by Delhi public works department New Delhi municipal council and ministry of road transport and highways (MoRTH, 2005). Subsequently the technology was given a go ahead for maintaining the roads of Delhi. It has also been included the MoRTH specification in clause 516 as slurry seal. IRC subsequently brought out IRC: 81-2008 'tentative specification for Microsurfacing'. NHAI has also issued a circular recommending Microsurfacing for renewal of wearing course for maintenance of national highways. Now Microsurfacing is used in many state of India for low volume road, highway and expressway maintenance.

Cold in-place recycling is an eco-friendly paving process for any road structure in irreparable condition. Recycling and reusing the existing pavement layer does away with the need for-and therefore the costs of purchasing and transporting fresh aggregate. During cold in-place recycling, two to five inches of the current road surface are pulverized to a specific aggregate size; mixed with a rejuvenating asphalt emulsion; and then reused, then and there. Overall labor costs are reduced. Because no heat is applied to the asphalt, cold in-place recycling reduces the noxious fumes and pollution associated with many other processes-what is safe for the environment is also safer for the road construction workers.

\section{Material and Methods Micro-surfacing}

Micro-surfacing is a mixture of polymer modified asphalt emulsion, mineral aggregate, mineral filler, water, and other additives, properly proportioned, mixed and spread on a paved surface in variable thick cross-section which resists compaction (ISSA, 2005).

\subsection{Materials}

The Microsurfacing shall consist of a mixture of an approved emulsified asphalt, mineral aggregate, water and specified additives which are describe below: 


\subsubsection{Emulsified Asphalt}

An emulsion is a thermodynamically unstable system consisting of at least two immiscible liquid phases one of which is dispersed as globules in the other globules in the other liquid phase stabilized by a third substance called emulsifying agent. In general, microsurfacingsuppliers supply the emulsion to the contractor along with a mix design. Typically the polymer is co-milled with the asphalt cement and emulsifier;

this is called CSS-1H emulsion. Different polymers or a combination of polymer can be added to the emulsion and these tend to be proprietary. Each polymer has its own unique properties that will enhance the performance characteristics of the emulsion. These performance characteristics could be stiffness of the emulsion at high temperatures, resistance to flushing, and elasticity of the emulsion at low temperatures. The amount and type of the emulsifier will affect the setting characteristics and compatibility of the emulsion.

The emulsified asphalt shall be a quick-set polymer modified cationic type CSS$1 \mathrm{H}$ emulsion and shall conform to the requirements specified in AASHTO M208 and ASTM 2397. It shall pass applicable storage and settlement tests. The polymer material shall be milled into the emulsion or blended into the asphalt cement prior to the emulsification process. The cement mixing test shall be waived for this emulsion. The residue of the emulsion shall have a minimum ring and ball softening point of $60^{\circ} \mathrm{C}$.

According to MoRTH, 2005 the emulsified bitumen shall be a Cationic rapid setting type as approved by the Engineer, conforming to the requirements as per IS: 8887. Where special mobile mixing machines are available, Class A4* rapid setting or K3* road emulsions to BS 434: Part 1 should be used to obtain very early resistance to traffic and rain. Generally, emulsion for Microsurfacing should be capable of producing slurry that will develop early resistance to traffic and rain and is sufficiently stable to permit mixing with the specified aggregate, without breaking during the mixing and laying processes.

\subsubsection{Aggregate}

The mineral aggregate used shall be the type specified for the particular application requirements of the slurry seal. The aggregate shall be crushed stone such as granite, slag, limestone, chat, or other high-quality aggregate, or combination thereof. To assure the material is 100 percent crushed, the parent aggregate will be larger than the largest stone in the gradation to be used. The smooth textured crusher fines shall have less than $1.25 \%$ water absorption. The aggregate shall be gray in color and clean and free from organic matter, other deleterious substances and clay balls. Oversized granular material and/or presence of clay balls will require the project to be stopped and shall meet the following requirements: 
Quality Tests: The aggregate should meet agency specified polishing values and these minimum requirements which is give in Table 2.1.

Table 2.1: Aggregate Quality Test

\begin{tabular}{|l|lc|l|}
\hline TEST & \multicolumn{2}{|l|}{ TEST METHOD } & SPECIFICATION \\
\hline $\begin{array}{l}\text { Sand Equivalent Value of Soils } \\
\text { and Fine Aggregate }\end{array}$ & T $176 \quad$ D 2419 & 45 Minimum \\
\hline $\begin{array}{l}\text { Soundness of Aggregates by Use } \\
\text { of Sodium Sulfate of Magnesium } \\
\text { Sulfate }\end{array}$ & T 104 88 & $\begin{array}{l}15 \% \text { Maximum } \\
\text { w/N2SO4 } \\
25 \% \\
\text { w/MgSO4 Maximum }\end{array}$ \\
\hline $\begin{array}{l}\text { Resistance to Degradation of } \\
\text { Small Size Coarse Aggregate by } \\
\text { Abrasion and Impact in the Los } \\
\text { Angeles Machine }\end{array}$ & & C 131 & $35 \%$ Maximum \\
& & & \\
\hline
\end{tabular}

The abrasion test is run on the parent aggregate

\section{Gradation}

The mix design aggregate gradation shall be within one of the following bands (or one recognized by the local paving authority) which is describing below:

Type I. This aggregate gradation is used to fill surface voids, address moderate surface distresses, and provide protection from the elements. The fineness of this mixture provides the ability for some crack penetration.

Type II. This aggregate gradation is used to fill surface voids, address more severe surface distresses, seal, and provide a durable wearing surface.

Type III. This aggregate gradation provides maximum skid resistance and an improved wearing surface. This type of micro surfacing surface is appropriate for heavily traveled pavements, rut filling, or for placement on highly textured surfaces requiring larger size aggregate to fill voids.

According to MoRTH the aggregate shall be crushed rock, or slag and may be blended, if required, with clean, sharp, naturally occurring sand free from silt pieces and organic and other deleterious substances to produce a grading as given in Table 500-33. The aggregates shall meet the requirements of the film stripping test (IS: 6241), and a suitable amount and type of anti-stripping agent added, as may be needed. 


\subsubsection{Mineral Filler}

Mineral filler may be used to improve mixture consistency and to adjust mixture breaking and curing properties. Portland cement, hydrated lime, limestone dust, fly ash, or other approved filler meeting the requirements of ASTM D 242 shall be used if required by the mix design. Typical use levels are normally 5 to 15 percent and may be considered part of the aggregate gradation. According to MoRTH, It is usual to use ordinary Portland cement, hydrated lime or other additives to control consistency, mix segregation and setting rate. The proportion of the additive should not normally exceed $2 \%$ by weight of dry aggregates.

\subsubsection{Water}

The water shall be free of harmful salts and contaminants. If the quality of the water is in question, it should be submitted to the laboratory with the other raw materials for the mix design.

According to MoRTH, 2005 Water shall be of such quality that the bitumen will not separate from the emulsion before the slurry seal is in place.

The $\mathrm{pH}$ of the water must lie in the range 4 to 7 , and if the total dissolved solids in the water amount to more than $500 \mathrm{ppm}$, the Engineer may reject it, or order the Contractor to conduct a trial emulsion mix to demonstrate that it does not cause early separation.

\subsubsection{Additives}

Additives may be used to accelerate or retard the break/set of the slurry seal. Appropriate additives, and their applicable use range, should be approved by the laboratory as part of the mix design.

Additive found in the study:

- Aluminum sulfate crystal

- Ammonium sulfate

- Inorganic salts

- $\quad$ Liquid aluminum sulfate

- Amines

- $\quad$ Anti-stripping agents

\subsection{Mixing process of micro-surface mix:}

The mix of micro-surface can be prepared at site or field; it depends mainly on the availability of material and transportation facility. The mixing procedure should follow which is obtained in laboratory. There are following type of mixing is given below 
- $\quad$ Batch mixing

- $\quad$ Continuous mixing

- $\quad$ Hand mixing

\subsection{Mixing procedure:}

Take the required gradation of aggregate, mix the water according to the surface area of aggregate in fine and course aggregate separately. After 10 minute put aggregate in the pre wet concrete drum, batch wise and mix emulsion in required proportion after that mix the cement when aggregate and emulsion mix properly and add left emulsion and mix it. The mixing time depends on the breaking time of emulsion which is given below.

\subsection{Laying procedure}

- $\quad$ Use rope to ensure straight edges \& cover thickness

- Use squeegee to spread

- Drag hessian burlap for smooth finish

- $\quad$ Only open to traffic once dry ( \pm 4 hours)

The breaking time of emulsion depend on the emulsion temperature which is given in

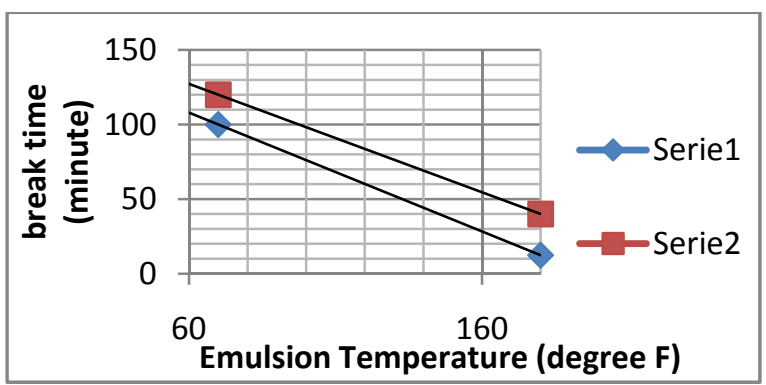

FIGURE 1 Relationship between temperature and emulsion breaking time (ISS A 2010a).

Figure 1 so the mix starts braking after this time.

\section{Results and discussion:}

\section{Environmental Impact:}

Pavement preservation is inherently green owing to its focus on conserving energy and raw materials, and reducing greenhouse gases by keeping good roads good (Chehovitz and Galehouse,2010).Microsurfacing's environmental footprint is lower than most common pavement preservation and maintenance treatments (Takamura et al. 2001). Figure 2 is from a study on the environmental impact of several commonly used pavement preservation and maintenance treatments. 
The study developed "eco-efficiency" indices for the five categories shown in the figure and found that Microsurfacing had a substantially lower environmental footprint than the other options (Takamura et al. 2001). This study does not include the reduced greenhouse gas emissions resulting from Microsurfacing's ability to greatly reduce traffic delays in work zones (Johnson et al. 2007). Additionally, the "risk potential" and "health effects" categories did not include the reduction in work zone

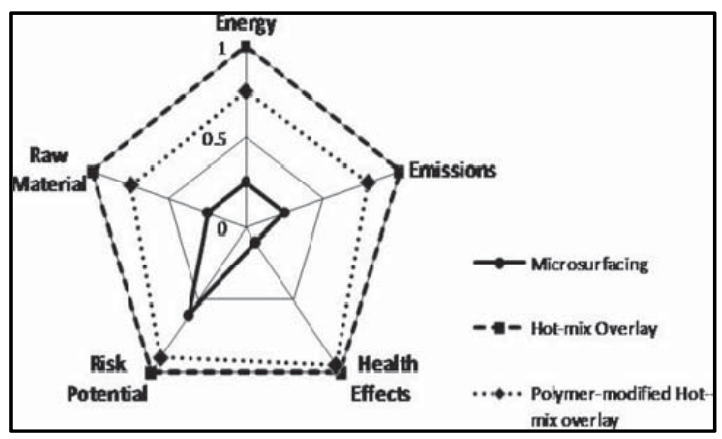

FIGURE 2: Microsurfacing environmental footprint compared with two types of pavement preservation overlays (Takamura et al. 2001)

accident risk inherent to microsurfacing (Erwin and Tighe 2008). Therefore, Microsurfacing's "true" footprint may be even smaller in relation to hot-mix asphalt options for pavement preservation and maintenance programs. When looking at options to address pavement preservation and maintenance issues, the engineer can use the environmental and safety benefits of Microsurfacing as possible justification to offset any marginal increase in construction cost versus other alternatives.

Figure 3 illustrates the output from that study (Takamura et al. 2001) and provides greater detail with respect to the greenhouse gas emissions, as well as information on raw material consumption. Both studies merely constructed asimplified snapshot of the comparative environmental impact of Microsurfacing. Neither included the impact of work zone delays nor the life safety benefits accrued from Microsurfacing owing to its ability to minimize the duration of work zone delays and increased congestion during pavement maintenance operations.

Dorchies (2008) performed several comparisons for different structure pavement sections and determine that for different structure yielding the same structure performance, energy and generate greenhouse gasses (GHG)emission can vary as much $80 \%$. 


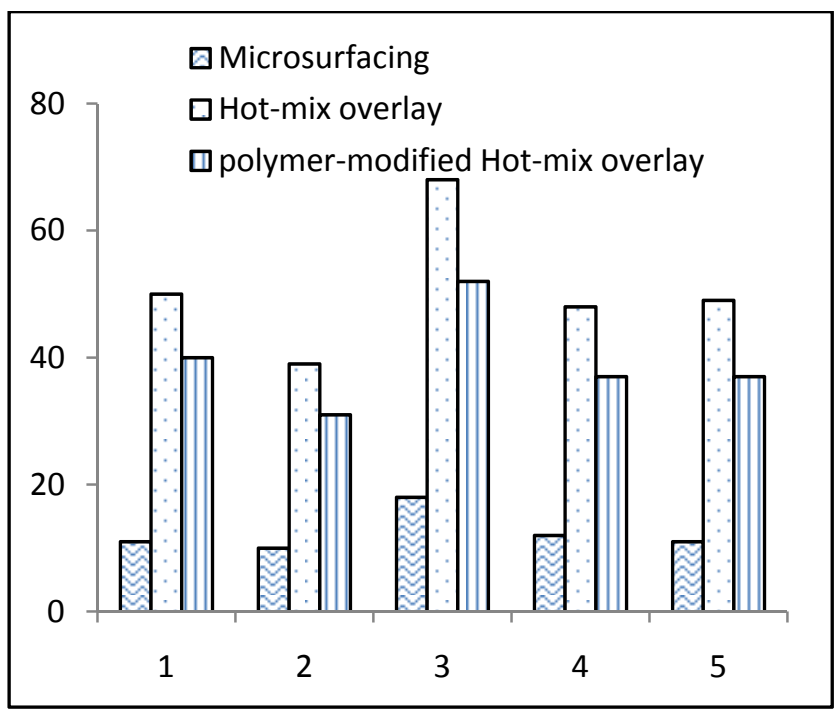

- 1-Energy, 2-CO2, 3-NO2, 4-Ozone and 5-Raw Material

FIGURE 3 comparative environmental impacts of three pavement preservation and maintenance treatments (adapted using data from takamuraet al.2001)

\section{Recycling of pavements}

Recycling of pavements is one such methodology which countries like USA, UK etc. are using from over 30 years. In United States of America,

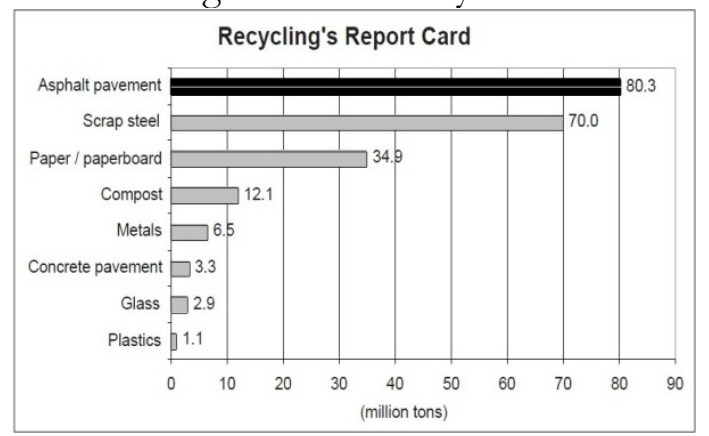

Figure 4: Products Recycled in USA (Asphalt Alliance)

products such as aluminum, plastic, paper, glass etc. are recycled but asphalt pavement is the product which is widely recycled (Asphalt Alliance). Various products which are recycled in United States of America and their percentages for the year 2010 are shown in Figure 4. It can be easily concluded that clear winner in recycling is asphalt pavement. 
The Federal Highway Administration reports that, out of 91 million metric tons of asphalt pavement 73 million metric tons are recycled i.e. an amount of $80 \%$ asphalt pavements are recycled in USA. The recycled material is used in rehabilitation projects, road widening projects, construction of embankments \& shoulders etc. Performance aspects of the recycled pavement also indicate that, recycled pavements perform equal to or better than the conventional mixes (Recycling Guidelines, 1997). All these statistics show a successful implementation of the recycling of pavements in USA.

The main reason behind the successful implementation of recycling is its benefits over the conventional methods. Two of the most highlighted benefits are the cost savings and preservation of the environment. These benefits prove to be significant because the Government wants to conserve budgets in every possible situation and presently the whole world is giving special attention to the environment by focusing on the 'Green Technology.' Adoption of recycling of pavements results in the savings of around $\$ 35-\$ 80$ per ton. So, if an amount of 15 ton is recycled per week, then cost savings of around $\$ 30,000-\$ 60,000$ can be achieved (Asphalt Alliance). This is significant amount of saving and if such a saving is achieved in India, much stress on the economy can be relieved by reducing the budgets allotted to the road development projects.

Hence, it can be concluded that recycling of pavements is an efficient solution for construction and maintenance of roads which offers enormous benefits like cost savings, preservation of virgin materials, preservation of environment etc. Hence, it is an open alternative for implementation on Indian roads to save the construction costs as well as sustain the sources of raw materials. If recycling of pavements is to be implemented in India, firstly current Ministry of Road Transport \& Highways (MORTH) specifications for road \& bridge works 2001, have to be updated to include specifications for recycling of pavements.

Recycling of pavements offers various advantages over the conventional methods of construction. Some of the advantages are mentioned below.

- Reduction in cost of construction: The construction cost of a bituminous pavement can be significantly reduced if recycling is adopted. As this methodology uses RAP to produce new materials, the requirement of new material gets reduced. Thus, material costs can be reduced.

- Preservation of virgin aggregates \& binder: Road construction projects have increased the material requirement and now days it has become difficult to find good quality of aggregates for road construction. Recycling of pavements offers use of existing material, thus sustaining the virgin aggregate sources. Also, virgin bitumen can be saved using recycling which is more advantageous as it is a petroleum product. 
- Preservation of pavement geometrics: The conventional rehabilitation technique is to overlay an existing pavement. This overlay increases the pavement thickness extensively causing a problem for pavement geometry and especially pavement drainage. Also in case of urban areas, the increased pavement thicknesses cause problems to the side-walks and also to the adjacent properties like houses, buildings, shops etc. Pavement recycling, if adopted, can sustain the thickness of a pavement to avoid such problems.

- Preservation of the environment: Pavement recycling can be implemented at ambient temperatures with the use of bitumen emulsion and cutback reducing the emissions and fuel consumption. Also, it can be implemented on site itself which eliminates the transportation of materials and in turn reduces the fuel consumption. Hence, recycling methodology preserves the environment and conserves energy.

\section{Conclusion}

The development of a new process or product requires substantial research and development before a sufficient level of reliability is achieved to enable implementation on a large scale.

Microsurfacing is a pavement preservation and maintenance tool with very few technical or operational limitations.

One tonne of HMA produce about $5.25 \mathrm{~kg}$ of carbon which can stop by implementing the Microsurfacing.

For the production of aggregate, GHG emission range is 2.5 to $10 \mathrm{kgCO}_{2} / \mathrm{t}$ and for asphalt it is $221 \mathrm{~kg} \mathrm{CO} / \mathrm{t}$.

Microsurfacing environmental footprint compared with Hot-mix Overlay and Polymer-modified Hot-mix Overlay is less.

Yielding of greenhouse gasses for the same structure performance, energy and generate greenhouse gasses (GHG) emission can vary as much $80 \%$.

Recycling of pavements offers various advantages over the conventional methods of construction (Hot-mix overlay) so it should be implement in Indian road construction.

To minimize energy use and GHG over the life of a pavement, all preservation treatment can be done by microsurfacing.

Acknowledgement: All authors are grateful to thank to the management of Indian Institute of Technology, Guwahati for giving all facilities. 


\section{References}

Erwin, T. and S.L. Tighe, "Safety Effect of Preventive Maintenance: A Case Study of Microsurfacing," TransportationResearch Record: Journal of the TransportationResearch Board, No. 2044, Transportation Research Board of the National Academies, Washington, D.C., 2008, pp. 79-86

Government of India Ministry of Road Transport and Highways 'Guidelines for Investment in Road Sector' (published in 2011)

Gransberg, D.D., "Life Cycle Cost Analysis of Surface Retexturing with Shotblasting as a Pavement Preservation Tool," Transportation Research Record,

International Slurry Surfacing Association (ISSA), Inspector's Manual for Slurry Systems, ISSA, Annapolis, Md.,2010a, 106 pp

ISSA Design Technical Bulletins (2005), International Slurry Surfacing Association

Journal of the'Transportation Research Board, No. 2108, Transportation Research Board of the National Academies, Dec. 2009, pp. 46-52

Ministry Of Road Transport and Highways (MORTH) (2008)

Takamura, K., K.P. Lok, and R. Wittlingerb, "Microsurfacing for Preventive Maintenance: EcoEfficient Strategy," International Slurry Seal Association Annual Meeting, Maui, Hawaii, 2001, p. 5 